\title{
ANÁLISE DA DISPOSIÇÃO DO LIXO NA CIDADE DE BELÉM-PA: O CASO DO LIXÃO DO AURÁ 1 .
}

\author{
Marlisson Lopes de Araújo ${ }^{2}$ \\ Silas Neves de Sousa ${ }^{2}$ \\ Vivian Camila Lobato ${ }^{2}$
}

\section{Resumo}

A questão dos resíduos sólidos afeta em geral todas as atividades, pessoas e espaço convertendo-se em um problema não só pelo o que representa em termos de recursos desperdiçados, mas também pela crescente incapacidade de se encontrar lugares adequados que permita a acomodação correta do lixo do ponto de vista ambiental. Neste presente trabalho procuramos esclarecer a disposição do lixo na cidade de Belém, assim como o lixo é jogado em ambientes inadequados afetando, sobretudo as características do solo e também de lençóis subterrâneos, uma vez que o lixão está localizado em uma estrutura geológica sedimentar muito recente e como tal facilita a contaminação devido suas características estratigráficas não consolidadas. Os problemas sociais são bem evidentes no local, devido o lixão está localizado próximo a área urbana o que facilita a entrada de pessoas que vem buscar no lixão seu sustento de cada dia, isso acontece principalmente pela falta de políticas públicas que possam atuar no sentido de fazer com que essas pessoas possam ter outra atividade fora do lixão do Aurá.

Palavras Chave: Resíduos Sólidos; Lixo; Belém; Aterro Sanitário; Aurá.

\begin{abstract}
The issue of solid waste in general affects all activities, personnel and space becoming a problem not only for what it represents in terms of wasted resources, but also by the increasing inability to find suitable places to allow the accommodation of the correct garbage the environmental point of view. In this work we seek to clarify the provision of garbage in the city of Bethlehem, as well as the rubbish is dumped in unsuitable environments affecting mainly the characteristics of the soil and groundwater also, since the landfill is located in a geological structure of sedimentary very recent and therefore facilitates the contamination due to their unconsolidated stratigraphic features. Social problems are very evident on the site, because the landfill is located near the urban area which

\footnotetext{
${ }^{1}$ Trabalho elaborado a partir de visita em campo no aterro sanitário de Belém/PA

${ }^{2}$ Autores, Acadêmicos do curso de licenciatura plena em Geografia do Instituto Federal de Educação, Ciência e Tecnologia do Pará (IFPA). Bolsistas do Programa Institucional de bolsas de Iniciação à docência- PIBID (CAPES), marlissonaraujo@hotmail.com, sscontador@gmail.com, vivian_camila2@hotmail.com.
} 
facilitates the entry of people who come to seek their livelihood in the landfill each day, this is mainly the lack of public policies that may act to the make these people may have other activity outside the landfill's

Aura.

Key-Words: Solid Waste, Trash, Bethlehem, Landfill; Aura.

\section{Introdução}

Desde o surgimento dos primeiros centros urbanos, a produção de lixo se apresenta como um problema de difícil solução. A partir da Revolução Industrial, com a intensificação da migração dos trabalhadores do campo para a cidade, aumentaram as dificuldades referentes à produção de resíduos sólidos de diferentes naturezas (domésticos, industriais, serviços de saúde, etc), os quais se constituem atualmente numa das principais fontes de degradação do meio ambiente. Com o avanço da urbanização e também com o aumento das atividades de extração e produção acarretam a produção de resíduos sólidos, os quais são depositados em locais inadequados do ponto de vista ambiental. Um dos problemas mais sérios que qualquer cidade enfrenta, mas que é particularmente grave nas enormes aglomerações urbanas é o lixo sólido, por isso abordamos neste trabalho uma discussão sobre o lixo na cidade de Belém buscando detectar possíveis danos ambientais que este pode causar ao meio ambiente, pois sabemos que o lixo tratado de maneira inadequada pode causar danos irreversíveis ao mesmo, assim como prejudicar a qualidade de vida das populações que vivem no entorno de áreas que servem de deposição inadequada do lixo. Fazemos uma discussão ampla em relação ao aterro sanitária do aurá onde é depositado todo o lixo coletado na cidade de Belém, Marituba, Ananindeua e Benevides.

\section{2. $O$ conceito de lixo}

O conceito de lixo que vigorou por muito tempo considera-o como "todo e qualquer tipo de resíduo resultante da atividade humana, toda matéria solida que não lhe é mais útil, funcional ou estética" (PEREIRA NETO, 1999, p. 9). Atualmente, devido à noção de que a natureza tende a não suportar os padrões de vida da população em face da necessidade de economia de energia e recursos naturais, é proposto um novo conceito. O lixo seria então "uma massa heterogenia de resíduos sólidos, resultantes das atividades humanas, os quais podem ser reciclados e parcialmente utilizados, gerando, entre outros benefícios, proteção a saúde pública e economia de energia e de recursos naturais" (PEREIRA NETO, 1999, p. 9)

Desde a realização da conferencia das nações unidas para o meio ambiente e o desenvolvimento-ECO-92-, "uma das questões amplamente discutida e considerada 
fundamental quanto à preservação do meio ambiente foi à crescente produção de resíduos sólidos em todo mundo" (SILVA \& ZAIDAN, 2004, p. 260). Várias são as propostas apresentadas por estudiosos, revelando o potencial valor econômico presente no lixo, levando o homem a criar mecanismo de reaproveitamento e reciclagem dos resíduos sólidos, visando à diminuição e controle do desperdício e conseqüentemente dos impactos ambientais.

O Brasil é considerado referência para o mundo por meio de seu modelo de reaproveitamento de materiais, atendendo assim ao estudo internacional compilado no relatório nosso futuro comum (ECO 92). Dentro deste contexto o IBGE - instituto Brasileiro de Geografia e Estatística, por meio de uma pesquisa sobre saneamento básico no Brasil, constatou a falência deste sistema. Verificou-se que $75 \%$ do lixo coletado no país são despejados a céu aberto. Quanto aos resíduos de serviços de saúde, 45\% dos municípios não possuem sequer a coleta especial e é misturado ao lixo domiciliar.

\section{Classificação do lixo}

Para determinar a melhor tecnologia para tratamento, aproveitamento ou destinação final do lixo é necessário conhecer sua classificação, pois o lixo possui uma complexa composição, onde atuam diversos elementos de diferentes fontes. O lixo pode ser classificado de acordo com sua natureza física, composição química, origem, riscos potencias ao meio ambiente, entre outros fatores. "Quanto sua natureza e estado físico, o mesmo pode ser classificado em estado sólido, líquido, gasoso e pastoso" (OLIVEIRA, 1997, p. 105).

No que se refere ao critério de origem e produção, Oliveira (1997), classifica o lixo urbano da seguinte forma:

LIXO URBANO: Formados por resíduos sólidos em áreas urbanas, onde se incluem os resíduos domésticos, os efluentes industriais domiciliares (pequenas indústrias de fundo de quintal), e resíduos comerciais.

LIXO DOMICILIAR: Formados por resíduos sólidos das atividades residenciais, contém muita quantidade de matéria orgânica, plástico, latas, vidro, papéis, etc.

LIXO COMERCIAL: Formados por resíduos sólidos das áreas comerciais, composto por matéria orgânica, papeis e plásticos de vários grupos.

LIXO PÚBLICO: Formado por resíduos provenientes de limpeza pública (areia, papéis, folhagem, poda de arvores).

LIXO ESPECIAL: Formados por resíduos geralmente industriais, merece tratamento, manipulação e transporte especial, são eles: pilhas, embalagem de agrotóxico, embalagem de combustíveis, de remédios ou venenos. 
LIXO INDUSTRIAL: Nem todos os resíduos produzidos por indústrias, podem ser designados como lixo industrial. Algumas indústrias do meio urbano produzem resíduos semelhantes ao domestico, exemplo disto são as padarias, os demais poderão ser enquadrados em lixo especial e ter o mesmo destino.

LIXO DE SERVIÇO DE SAÚDE: Os serviços hospitalares, ambulatoriais, farmácias, são geradores dos mais variados tipos de resíduos sépticos, resultados de curativos, aplicação de medicamentos que em contato com o meio ambiente ou misturado ao lixo domestico poderão ser patógenos ou vetores de doenças. Eles devem ser destinados a incineração.

LIXO ATÔMICO: Produto resultante da queima de combustível nuclear, composto de urânio enriquecido com isótopo atômico 235. A elevada radioatividade constitui um grave perigo a saúde da população e por isso deve ser enterrado em local próprio e inacessível.

\section{4. $O$ caso de Belém - PA}

O município de Belém está localizado na região norte do Brasil, capital do estado do Pará, possuindo uma área de aproximadamente $1.065 \mathrm{Km}^{2}$. O clima equatorial quente e úmido apresenta uma parte continental de terras firmes e outra insular com mais de dez ilhas, somando mais de $65 \%$ do total de terras do município. Formada pelos municípios de Belém, Ananindeua, Benevides, Marituba e Santa Bárbara do Pará, a Região Metropolitana de Belém (RMB), no Pará, conta com quase 2,1 milhões de habitantes, distribuídos por uma área de aproximadamente 1,8 mil km². Em 2006, o montante de lixo produzido pela Grande Belém, chegou a 386 mil toneladas, o que representa a produção de cerca de 184 quilos por habitante naquele ano. Esses dados foram apresentados pelo pesquisador Netuno Leão, do Instituto do Homem e Meio Ambiente da Amazônia (Imazon), durante o seminário "Resíduos Sólidos, Coleta Seletiva Solidária e Responsabilidade Socioambiental”, promovido pelo Museu Paraense Emilio Goeldi (MPEG), entre os dias 9 e 11 de setembro, no Auditório Paulo Cavalcante, do Campus de Pesquisa da Instituição. Para ele, o acondicionamento adequado de todo esse lixo ainda representa um ponto de interrogação para a capital paraense.

"O destino final do lixo é um dos maiores problemas da Região Metropolitana de Belém", disse o pesquisador, durante a apresentação "Lixo: um desafio sustentável para Belém”, ocorrida na tarde de quarta-feira, dia 10. Leão acredita que Belém só chegará a uma alternativa adequada para o destino final do lixo por meio de uma cooperação com os demais municípios da Região Metropolitana. "Não existe uma resolução isolada", suscita. Grandes impactos ambientais e sociais são causados pela crescente tendência de urbanização da 
população mundial, segundo o especialista do Imazon. "Em 2030, 80\% da população mundial viverá em cidades. Atualmente, mais de um bilhão de pessoas vivem em favelas", afirma o pesquisador, complementando que a "redução do impacto ambiental pode evitar 13 milhões de morte". Mas por onde iniciar essa redução, que, de certa forma, implica numa revolução de valores? Leão afirma que a difusão da noção de cidade sustentável pode ser o primeiro passo. “A população urbana de Belém, hoje, é 97,56\%", diz, sugerindo que a coleta seletiva, "que ainda é incipiente na cidade", pode ser um bom começo. "O lixo gera novos produtos e energia", garante Netuno Leão. Na opinião do estudioso, o acompanhamento efetivo do lixo, que é produzido individualmente por empresas ou cidadãos, pode colaborar para a materialização do conceito de cidade sustentável. "O lixo é seu e você tem que saber o que acontece com ele", sugere. A redução na produção de lixo, a ampliação no acesso da população à coleta seletiva e o estímulo à reutilização e à reciclagem, além do acondicionamento adequado, também podem contribuir para a instauração da sustentabilidade em Belém. (Agência Museu Goeldi).

De acordo com o IBGE (Instituto Brasileiro de geografia e Estatística), a estimativa da população de Belém é de 1.408 .847 habitantes, dados de 2007, cuja geração de resíduos urbanos destinado ao aterro é de 1.035 t/dia incluindo os resíduos domiciliares, hospitalares, feiras, mercados e parte de entulhos. "Os valores anuais de coleta de lixo domiciliar em Belém aumentaram de 180 mil toneladas, em 1996, para 253 mil toneladas, em 2001" (PMB, 2002).

O município de Belém é responsável por grande parte do lixo produzido na Grande Belém. "Em 2005, produziu cerca de 524 mil toneladas de lixo e ocupou a oitava posição entre as capitais do Brasil. Nesse ano, a sua produção per capita foi de 0,58 quilo" (Imazon, 2007, p. 61). Ross (2008, p. 218) afirma que:

\footnotetext{
O lixo gerado nas cidades tem-se tornado cada dia mais problemático por duas razões: a população urbana tornou-se muito numerosa e gera volumes de lixo cada vez maiores; a evolução técnica e o processo crescente de desenvolvimento industrial geram, cada vez mais, tipos de lixo que a natureza por si só não consegui destruir, como os plásticos e vidros, que não são biodegradáveis.
}

De acordo com nossa pesquisa de campo o lixo na cidade de Belém é despejado em locais impróprios, espalhados pelas vias públicas e muita das vezes jogadas em canais de drenagem que cortam a cidade de Belém. Um dado importante que podemos destacar é que “em 2005, cerca de 524 mil toneladas de lixo (65\%), incluindo-se os entulhos de construção, 
foram destinados ao Aterro Sanitário do Aurá, enquanto o restante (35\%) do lixo coletado, ou seja, 277 mil toneladas foram para outras unidades de disposição da Grande Belém” (Sesan, Seinf e Snis 2005). Porém Belém ainda enfrenta um problema sério em relação à coleta do lixo, principalmente nos bairros periféricos da cidade onde o serviço de coleta é incipiente ou inexiste, foi o que constatamos em nossa pesquisa. A estimativa de produção de lixo por Belém é de 1350 ton/dia, Ananindeua 37,21 ton/dia, Marituba 236,14 ton/dia, resultando no total de 1623,35 ton/dia que são destinados ao aterro sanitário do aura.

Apesar de está sendo desenvolvida a questão da coleta seletiva em alguns pontos, porém é muito grande a quantidade de lixo que não é separado e tratado. Sabemos que a disposição inadequada do lixo na cidade pode causar sérios problemas como: entupimento de córregos, pontes, bueiros, e conseqüentemente provocando enchentes na área central da cidade. Em Belém a questão da coleta seletiva é um projeto que ainda é insatisfatório, enquanto que grande quantidade de lixo produzida tanto pela população quanto pelos os outros setores públicos e privados da cidade chega a mais de 23 mil toneladas por mês e 35\% de todo esse material que poderia ser reciclado ainda vai para o lixão do aurá. A coleta seletiva favorece o reaproveitamento das embalagens do lixo urbano e pode gerar uma receita para os catadores. A coleta seletiva tem obtido avanços significativos em cidades como Porto Alegre e Curitiba. Esse tipo de coleta pode ser realizado em domicilio (precisa ter recipiente especifico) por catadores, em postos de entrega voluntária ou em postos de troca. Em qualquer um dos casos, a eficiência do sistema depende da cooperação da sociedade organizada e dos empresários e não apenas da prefeitura.

A área do aterro de Belém, localizada em Ananindeua recebe diariamente centenas de toneladas de materiais que poderiam ser reciclados ou reutilizados. Estes materiais estão sendo lançados hoje em uma área que em alguns anos estará saturada, além de provocarem de alguma forma, problemas ambientais, em função de sua degradação ou decomposição e reação com o solo, provoca também problemas de saúde, principalmente das populações que vivem próximos do lixão.

Segundo a SESAN, no lixo despejado no aterro do Aurá e separado para reciclagem em 2006, encontrou-se;

$$
\begin{aligned}
& \text { - } \quad 35 \% \text { de garrafas plásticas } \\
& \text { - } \quad 25 \% \text { de papel } \\
& \text { - } \quad 19 \% \text { latas de alumínio e } \\
& \text { - } \quad 17 \% \text { papelão }
\end{aligned}
$$


Como consequiência, o acúmulo de resíduos sólidos na área urbana tem gerado sérios problemas e pode gerar problemas futuros e mais graves para o município, como a degradação do meio ambiente e a necessidade de construção de outro aterro, implicando em mais dificuldades.

\section{Cooperativas: cooperativa cidadania para todos}

A cooperativa cidadania para todos foi fundada em 19 de maio de 2005, nela atualmente trabalham 45 pessoas, que são contratadas pela empresa Centro de Reciclagem da Amazônia (CRA). Esta associação trabalha somente com o chamado plástico duro, sendo que esse tipo de plástico possui 32 qualidades ou tipos, porém segundo entrevista realizada com a coordenadora da cooperativa esse tipo de plástico será substituído a partir de julho de 2009 pelo plástico fino, chamado pelos trabalhadores de filme, quando serão contratados mais 20 funcionários.

\section{Galpão da Cooperativa Cidadania para todos: alternativa para muitas famílias que antes trabalhavam em condições desumanas no lixão do Aurá.}

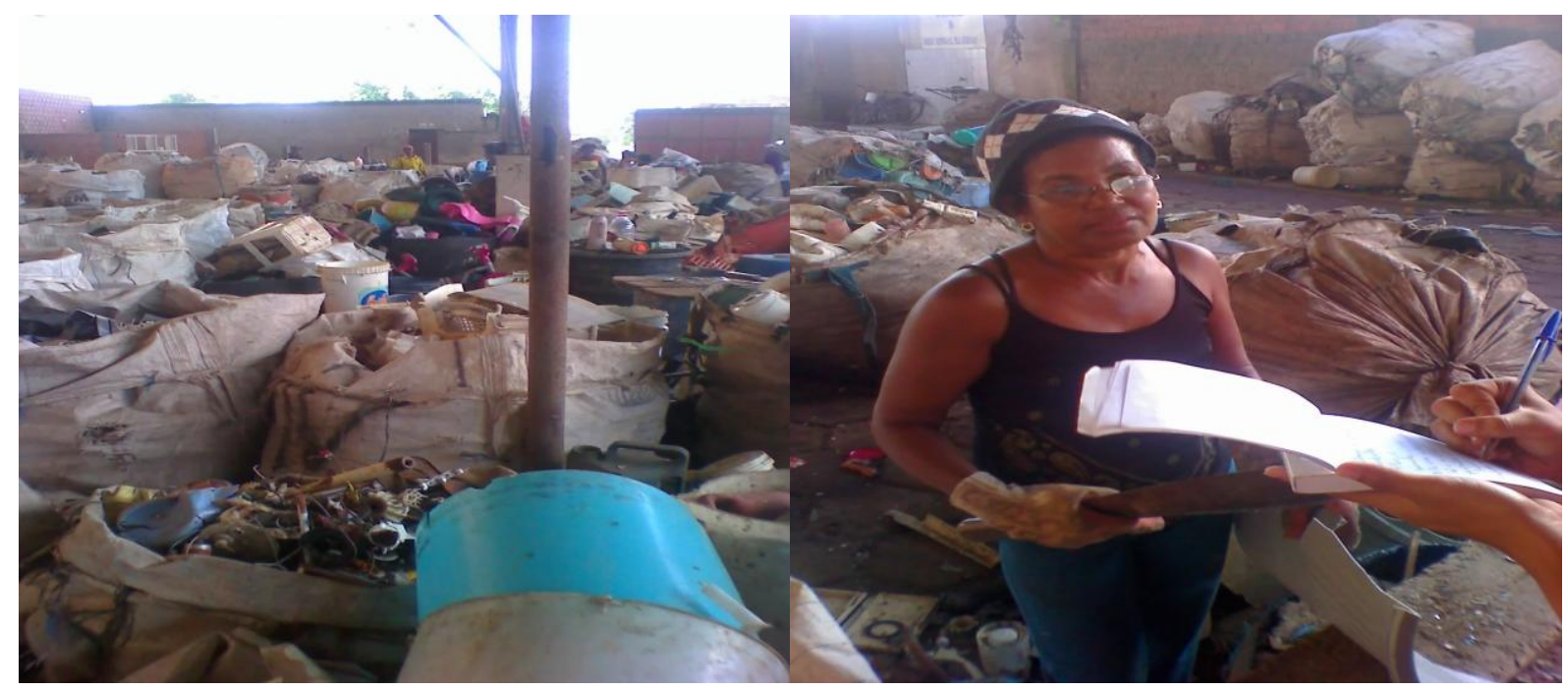

Figura 1- Salão de deposição do material separado pelos trabalhadores da CRA, ao lado dona Maria Lúcia, vice-presidente da cooperativa. Foto dos autores.

A cooperativa recebe 25 toneladas de plástico por semana, comprados pela empresa CRA dos catadores independentes que trabalham no lixão do Aurá, que fica localizado próximo à associação. Nesta, o material recebido é cortado e separado por cor pelos trabalhadores, que na maioria das vezes trabalham em dupla durante o dia inteiro, das sete da manhã até as seis ou sete da noite. A renda é paga por semana, segundo a produção de cada trabalhador. Todos os dias, depois das cinco da tarde, o material cortado e separado é pesado. Sendo que aos sábados a empresa CRA paga nove centavos por quilo para quem selecionou 
mais de 2.500 quilos na semana e oito centavos por quilo para quem selecionou abaixo deste limite. Segundo nossa pesquisa, os trabalhadores, para terem direito aos benefícios do governo, pagam o INSS mensalmente. O material separado pelos trabalhadores é triturado e compactado nas maquinas da empresa e exportado por esta para São Paulo para ser transformado em novos produtos.

Dona Maria Lúcia, vice-presidente da cooperativa trabalha desde o inicio da mesma, tem 55 anos de idade e estudou até a terceira série do ensino fundamental. Antes, trabalhava como catadora no lixão, disse que na cooperativa as condições de trabalho são melhores e mais seguras e a renda ainda é maior. "aqui é melhor, lá eu trabalhava no sol e na chuva, fui assaltada várias vezes, pegava em todo tipo de imundice, e a lama às vezes vinha até minha cintura, aqui não acontece isso, porque só trabalhamos com plástico, conclui dona Maria”.

\section{Cooperativa de Trabalho dos profissionais do Aurá (COOTPA)}

Os catadores de lixo do aterro do Aurá fornecem material reciclado para cinco empresas no estado do Pará. Criada em maio de 2001, a COOTPA tem 197 associados e está recebendo auxílio técnico da Incubadora de cooperativas da UFPA. Entretanto, apenas 60 de um total de 459 catadores cadastrados pela Sesan preferem destinar os resíduos através da cooperativa, enquanto o restante comercializa os materiais reciclados via atravessadores (IMAZON).

\section{Tratamento e disposição final}

Tendo sido gerado o lixo, há varias formas de tratar-lo ou dar-lhe uma disposição final. Cada uma das alternativas deve ser analisada levando em consideração a viabilidade, suas vantagens e desvantagens. Tendo em vista a relevância desses fatores, somente a reciclagem pode ser encontrada como um dos fatores que recebe um determinado tipo de tratamento na cidade de Belém.

INCINERAÇÃO: Processo de tratamento de lixo de alta tecnologia exige alto investimento. O volume do lixo é reduzido a $25 \%$ do seu volume, no entanto, produz cinzas tóxicas cuja destinação final (aterro sanitário) é ainda questionável.

COMPOSTAGEM: Tratamento da matéria orgânica presente no lixo através de um processo aeróbio em que ela é transformada em húmus, material mineralizado que pode ser utilizado como adubo para plantas. Esse processo, paralelo ao uso do aterro sanitário, aumentara sua vida útil, uma vez que retira $60 \%$ dos resíduos que seriam nele depositados. 
RECICLAGEM: A reciclagem diminuirá o volume de lixo a ser depositado no aterro, visto que serão retirados dos resíduos aqueles que são potencialmente recicláveis (papel, papelão, plástico, vidro etc.). Nesse caso será necessário uma usina de triagem para a separação do lixo e a implementação da coleta seletiva auxiliará a reciclagem, porém esse tipo de serviço de tratamento do lixo como uma usina de triagem é inexistente na cidade de Belém aja vista que a separação do lixo é feita pelos catadores dentro do lixão.

ATERRO SANITÁRIO: Disposição final do lixo de forma adequada, cuidando para não haver contaminação do solo e da água dos lençóis subterrâneos.

\section{Análise e Disposição do Lixo na Cidade de Belém - PA: o Lixão do Aurá}

A área do aterro de Belém, localizada em Ananindeua recebe diariamente centenas de toneladas de materiais que poderiam ser reciclados ou reutilizados. Estes materiais estão sendo lançados hoje em uma área que em alguns anos estará saturada, além de provocarem de alguma forma, problemas ambientais, em função de sua degradação ou decomposição e reação com o solo. O aterro sanitário do Aurá foi Fundado em 1987, mais conhecido como "lixão do Aurá" está localizado no bairro Águas lindas, município de Ananindeua na grande Belém, ocupando uma área de aproximadamente 130 ha e é constituído de 10 células de deposição de lixo sendo que está sendo utilizada a décima célula. O lixão do Aurá recebe lixo de três municípios da região metropolitana de Belém: Belém, Ananindeua e Marituba, diariamente são depositados no Aterro cerca de 1700 toneladas de lixo incluindo: domiciliar, comercial, industrial, podas de árvores, animais mortos, alimentos deteriorados, objetos volumosos e etc., não sendo permitido o depósito de material hospitalar. Entretanto não há qualquer tipo de fiscalização que impeça que esses materiais sejam depositados no aterro, já que muitas vezes o lixo hospitalar é misturado com o lixo doméstico. A propósito disso, Ribeiro e Gunther (2003) In Calderoni (2000) apontam que:

\footnotetext{
A disposição inadequada do lixo urbano, tanto pela população como pelas prefeituras, de um modo geral, tem causado toda a sorte de impactos. Essa prática tem reflexos sanitários e econômicos nas atividades cotidianas da própria vizinhança, como o entupimento de bocas-de-lobo e a redução do leito de drenagem dos rios, contribuindo para as enchentes e desmoronamentos de encostas, devido à instabilidade dos depósitos, em épocas de chuva.
}

Além disso, os materiais depositados no aterro produzem o chorume (líquido que resulta da umidade natural do lixo), este líquido é produzido devido à decomposição da matéria orgânica pelas enzimas liberadas pelas bactérias, exala um cheiro insuportável e contamina o lençol freático. Esse é um problema que tem preocupado os ambientalistas, o clima quente gera rápida decomposição do lixo orgânico que devido à grande quantidade de 
chuvas penetra o solo e atingem os lençóis freáticos, o que representa uma grande ameaça para o lagos da região, como o lago Água Preta que está localizado a 2 km do Lixão do Aurá, e é responsável pelo abastecimento de água potável na região.

Atualmente o lixão do Aurá não possui padrões de um aterro sanitário, é um depósito de lixo a céu aberto, a grande quantidade de lixo nele depositada é cada vez maior não havendo seleção do material coletado, o que atrai animais e insetos que podem transmitir inúmeras doenças e colocar em risco a saúde das pessoas que trabalham como catadoras e a população que mora entorno do lixão.

\section{A dura realidade de quem necessita do lixo para sua sobrevivência}

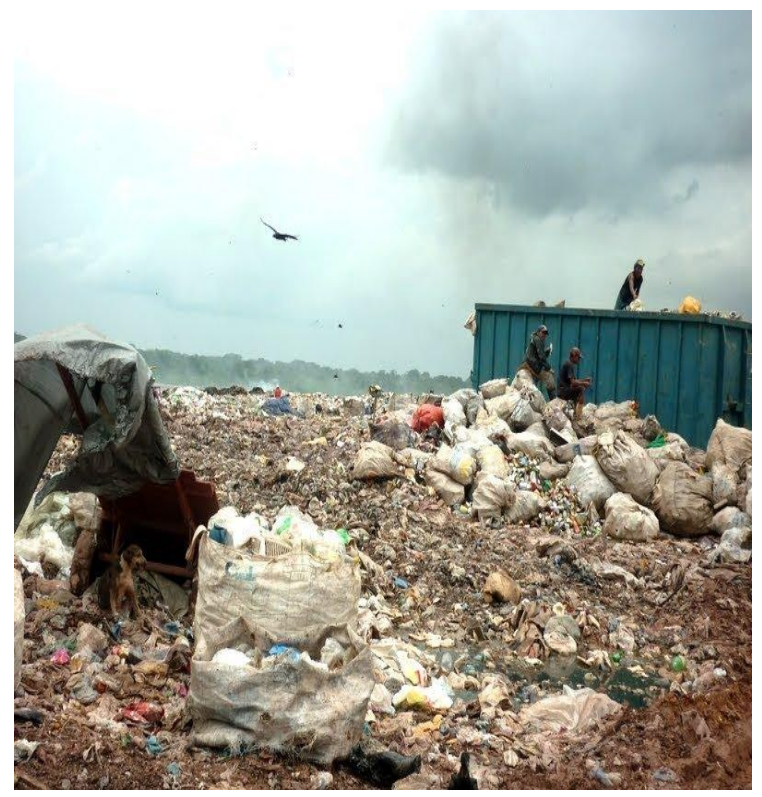

Figura 2: A foto representa a verdadeira imagem do aterro sanitário do Aurá, ou seja, lixão do Aurá. Foto dos autores

Não só um problema ambiental o "lixão do Aurá" se tornou também um problema social, com o passar do tempo este se tornou a maior fonte de renda para as pessoas que trabalham e moram em volta do aterro, em meio à dura e difícil realidade de busca pela sobrevivência os catadores de materiais recicláveis (garrafas pet, plásticos, papelão, alumínio e etc.) têm que aprender a conviver com a violência existente no local. Tráfico de drogas, roubos, ameaças e até a ocultação de corpos, são presenciados por quem trabalha no aterro sanitário.

Com o passar do tempo o aterro se firmou como parte da vida de muitas pessoas: adultos, jovens e crianças, trabalham durante uma jornada de cerca de dez horas ininterruptas, para conseguir uma remuneração diária de aproximadamente cinqüenta reais, muitas famílias 
chegam a fazer revezamento de pessoas para conseguir uma boa renda. Observou-se também que muitos catadores e moradores próximos do "lixão do Aurá" possuem um nível de escolaridade baixo, apenas o ensino fundamental incompleto o que dificulta uma possível ascensão ou quebra do ciclo da pobreza.

\section{Lixo, solução ou um problema? O lixo não é simplesmente lixo, dentre outras coisas ele serve de subsídio para o sustento de muitas famílias}

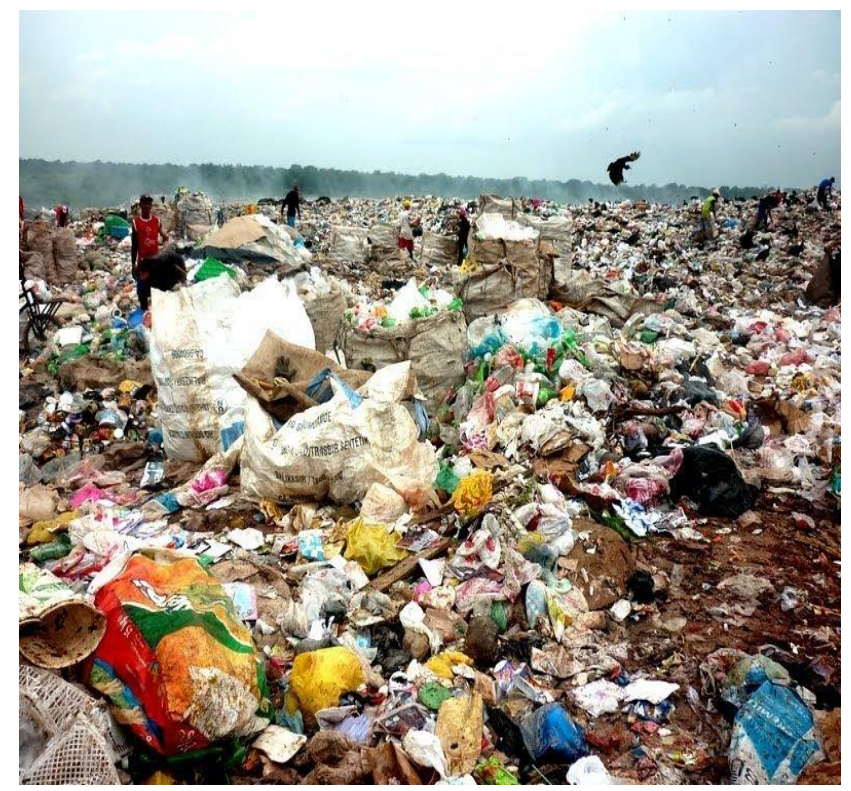

Figura 3: Foto do lixão mostrando trabalhadores convivendo com urubus e vários outros tipos de vetores que são encontrados no lixão. E há quem diga que o lixão funciona como um aterro sanitário, seguindo todas as normas e regulamentos. Foto dos autores.

\section{Características Geológicas}

O lixão do aurá está localizado sobre os sedimentos pós-barreiras o que segundo Souza e Anjos (2004, p. 158) "não oferecem uma proteção efetiva à penetração de contaminantes". Levar essas características geológicas em consideração quando da construção de um aterro sanitário é muito importante uma vez que a partir desses estudos podemos fazer as devidas avaliações se o local é ou não propício a construção do aterro.

"O conjunto de rochas que compõem a região em estudo e adjacências faz parte da bacia sedimentar da Amazonas, cuja área emersa é conhecida como Bacia Sedimentar do Marajó" (Oliveira apud Ludwing, 1996; Schaller et al ., 1971).

Os litotipos que compõem a moldura geológica da área estão dentro dos domínios das coberturas fanerozóicas e são representados por uma sequiência carbonática em subsuperfície, 
denominada Formação Pirabas, de idade miocênica, e recobertos por sedimentos clásticos do grupo Barreiras, de idade terciária, Cobertura Detrítico Laterítica, Cobertura sub-recente e Cobertura Aluvionar Recente, de idade quaternária.

A partir da década de 1990 aumentaram os estudos sobre os sedimentos que compõem a Formação Barreiras, onde os pesquisadores vêm desenvolvendo trabalhos geológicos na busca de um melhor entendimento dessa formação. Ao longo destes estudos, os autores têm obtido resultados bastante relevantes acerca desses sedimentos, onde designaram os sedimentos subaflorantes e aflorantes na região metropolitana de Belém e no nordeste do Pará, de Formação Pirabas, Grupo Barreiras e Pós-Barreiras.

Diante do exposto, depreende-se que são necessários estudos mais detalhados na área de geologia focalizando a área em estudo, objetivando avaliar os riscos potenciais que o lixo representa para o meio ambiente e para a saúde pública.

\section{Proposta de aterro sanitário: alguns requisitos}

Para a elaboração de um projeto de construção e implementação de um aterro sanitário, vários fatores devem ser considerados. Em primeiro lugar deve-se considerar a localização do mesmo que precisa está próximo a zona urbana a fim de ter menores gastos com o transporte do lixo e ao mesmo tempo longe o suficiente da população, do crescimento da cidade para evitar qualquer contato das pessoas com o lixo. O local escolhido precisa ter acesso garantido o ano todo, especialmente no período das chuvas.

Tendo sido escolhido o local depois de analisar os fatores preponderantes, passamos as exigências dos órgãos ambientais para que o aterro tenha ao final uma licença de funcionamento.

IMPERMEABILIZAÇÃO: É indispensável a impermeabilização do local afim de evitar qualquer contaminação do solo ou do lençol freático. Para tanto, usa-se uma camada de argila compactada e quando necessário um revestimento com um tipo de manta impermeabilizante.

DRENAGEM E TRATAMENTO DO CHORUME: A decomposição do lixo não deixará de ser anaeróbica e produzirá o chorume. A diferença é que no aterro sanitário o chorume deve ser retirado do local de depósito através de canalizações perfuradas e levado as lagoas de tratamento.

RETIRADA DE GASES: Os gases produzidos na decomposição do lixo devem ter uma canalização vertical especial para poderem ser liberados. 
DRENAGEM DE ÁGUAS PLUVIAIS: A água da chuva não deve entrar no aterro e por isso elabora-se um sistema que intercepte a água antes que ela chegue na área de deposição do lixo e destina-a para fora do aterro.

RECICLAGEM - OS 4rs: Uma alternativa para a vida útil do aterro é a retirada do lixo que pode ser reciclado. Pra tanto, cria-se uma usina de triagem em local próximo ao aterro sanitário para separar materiais como papel, papelão, metais, vidros etc. Para a realização desta atividade, normalmente existe uma cooperativa de catadores que viviam do lixão e a partir da criação do aterro trabalham com mais dignidade e em melhores condições. Algumas comunidades optam pela reciclagem, pois a venda do material reciclável pode servir de sustento para muitas pessoas, os adeptos da reciclagem usam os 4rs para defini-la melhor: Reduzir, Racionalizar, Reutilizar e Reciclar.

\section{Política e Legislação}

As questões ambientais entraram em pauta nas discussões mundiais à partir da Conferência de Estocolmo na Suécia em 1972. Após esta conferência foi instituído o Programa do Meio Ambiente das Nações Unidas. O relatório de Brundtland em 1987 onde o tema "Desenvolvimento sustentável" recebeu maior divulgação, cuja abordagem tenta conciliar as questões sociais, econômicas e ambientais. Em 1992 foi à vez da Conferência da ONU no Rio de Janeiro "RIO-92", que adotou a Agenda 21 no propósito da redução da degradação em todo mundo.

Muitos países já têm leis para o controle da poluição e programas que incentivam a reciclagem do lixo.

No Brasil na área ambiental temos:

- Lei no 5.318 de 26/09/67 - que instituiu a Política Nacional de Saneamento e cria o CNS

- $\quad$ Lei no 6.398, de 31/08/81 - Dispões sobre a Política Nacional do Maio Ambiente.

- Lei no 9.605, de 12/02/98 - Dispões sobre Crimes Ambientais.

\section{Método e Técnica}

Sabendo da grande problemática ambiental que se apresenta para a humanidade em virtude do aumento populacional com predomínio de formas inadequadas de ocupação e 
utilização dos espaços e recursos naturais, decidiu-se levantar alguns aspectos a respeito da disposição do lixo na cidade de Belém PA.

Neste trabalho, é analisada a situação dos resíduos sólidos urbanos no Brasil e apresenta uma análise das condições de seu tratamento no aterro sanitário do Aurá.

Para fundamentação do trabalho, foram levantadas algumas bibliografias sobre o assunto e realizadas visitas de conhecimento do aterro sanitário de Belém, com o fim de coletar alguns dados e registrar as características do local. Esta pesquisa foi realizada levando em consideração temáticas sobre resíduos Sólidos, meio ambiente, coleta seletiva, reciclagem, geologia, entre outros pertinentes para compor o resultado da nossa pesquisa.

\section{Resultados}

É preciso uma qualificação técnica dos municípios, um maior envolvimento da sociedade junto à administração para que sejam realizados projetos que possibilitem alcançar financiamentos e recursos, e que fique claro na consciência das pessoas que o lixo não é necessariamente lixo, entre outras formas ele serve de sustento para muitas famílias, por isso a importância da sua disposição final adequada. A redução da produção de lixo, especialmente os mais poluentes é um dos princípios fundamentais para uma cidade saudável e para o desenvolvimento urbano sustentável.

Através dessa pesquisa constatamos que é urgente estudos mais detalhados em relação aos problemas ambientais causados pela disposição inadequada do lixo, foram evidenciados futuros problemas relacionados aos córregos e aos lagos próximos da área como também a degradação do solo, pois o processo de decomposição do lixo libera substancias nocivas ao meio prejudicando a qualidade dos ambientes naturais da região. Esperamos que através deste trabalho, as pessoas possam tomar consciência de que o lixo não é necessariamente lixo, entre outras formas ele serve de sustento para muitas famílias, por isso a importância da coleta seletiva.

\section{Considerações Finais}

Um dos maiores desafios ambientais que Belém enfrenta, sem dúvida é o problema do lixo urbano. Para tanto são necessárias alternativas.

Como proposta, sugere-se Políticas Públicas para a melhoria e o aumento da acessibilidade da população ao serviço de coleta de lixo de forma satisfatória aliada a programas contínuos de educação ambiental, promovendo uma maior participação da sociedade na luta pela melhoria da qualidade de vida e o alcance de uma completa cidadania. 
A geografia nesse contexto tem um papel de fundamental importância dado seu caráter abrangente, podendo contribuir de forma significativa nas análises ambientais. Portanto, é prioritário o desenvolvimento social e humano, ao contrário do que se verifica no atual modelo de desenvolvimento econômico. Após a análise de várias fontes, fica evidente a importância da reciclagem, pois são inúmeros os benefícios gerados para a economia, para o meio ambiente e para a sociedade, que ao devolver o que era considerado lixo para a natureza de maneira adequada, respeita sua capacidade de assimilação e garante um ciclo que nos permite almejar o desenvolvimento sustentável e uma conseqüente melhoria na qualidade de vida. Para que a reciclagem aconteça de forma integrada, maximizando seus benefícios, se faz necessário a participação de três agentes, cada um deles atuando de forma complementar aos demais. São eles: a sociedade, que consome e deve dispor corretamente o lixo residencial, separando adequadamente os resíduos secos e os úmidos, o poder publico, que tem por responsabilidade gerenciar os resíduos sólidos urbanos, recolher e dar destino adequado ao lixo domiciliar, criando sistema de coleta seletiva e triagem do material coletado, e o setor produtivo, o qual deve criar estruturas capazes de receber e processar o que foi separado.

\section{Referências Bibliográficas}

AMENDOLA, D. P; BERNADES, A. M; FARIA, A. L. L. Análise da Disposição do Lixo na Cidade de Viçosa-MG In: Anais do XI Simpósio Brasileiro de Geografia Física Aplicada05 à 09 de Setembro de 2005-USP

CALDERONI, Sabetai. Os Bilhões Perdidos no Lixo. São Paulo: Humanitas, 2000.

CERES-PA. Comitê Estadual de Resíduos Sólidos do Estado do Pará.

COMPROMISSO EMPRESARIAL PARA RECICLAGEM. Disponível on-line em http://www.cempre.org.br acesso em Abril de 2009.

IMAZON in: ALENCAR, C; LEÃO, N; VERÍSSIMO, A. Belém Sustentável 2007. Belém: Instituto do Homem e Meio Ambiente da Amazônia, 2008.

MPEG - Museu Paraense Emílio Goeldi (Agencia Museu Goeldi), 2007 
OLIVEIRA, A.H 1997. Metais pesados nos arredores de depósitos de lixo de Belém-Pa. Belém. Universidade Federal do Pará. Centro de geociências. (Dissertação de Mestrado, p. 105).

PMB. Prefeitura Municipal de Belém. Disponível em: <http: /www.prefeituradebelem.org.br/>. Acesso em: 22 maio 2009.

PEREIRA NETO, João Tinoco. Quanto vale nosso lixo. Projeto verde vale, Copyright IEF/UNICEF. Viçosa, 1999.

ROSS, Jurandyr L. Sanches. Geografia do Brasil. Ed. rev. E ampl., 1. Reimpre. - São Paulo: Editora da Universidade de São Paulo, 2008. - (Didática; 3).

Secretaria Municipal de Saneamento (SESAN), 2005.

SOUZA, Eliene L. DE ANJOS, Gisele C. dos. Contaminação das Águas Subterrâneas: Uma Visão Parcial da Situação de Belém e dos Problemas Decorrentes In: UHLY, Steven; SOUZA, Eliene Lopes de (organizadores). A Questão da Água na Grande Belém. Belém: Casa de Estudos Germânicos, 2004. 